\title{
ABORDAGEM VIDEOLAPAROSCÓPICA DE CISTO ESPLÊNICO NÃO PARASITÁRIO
}

\author{
LAPAROSCOPIC APPROACH OF A NONPARASITIC SPLENIC CYST
}

\author{
Marcos Bettini Pitombo, TCBC-RJ ${ }^{1}$ \\ Paulo Roberto Falcão Leal, TCBC-RJ ${ }^{1}$ \\ Renato Maranhão de Albuquerque, RCBC-RJ ${ }^{2}$
}

\section{INTRODUÇÃO}

Cistos esplênicos são $\operatorname{raros}^{1-5}$. Os cistos não parasitários podem ser classificados em verdadeiros (congênitos ou neoplásicos) ou pseudocistos (pós-traumáticos ou sem causa definida), de acordo com a presença ou ausência, respectivamente, de um epitélio de revestimento interno do cisto $^{1-5}$. Nas áreas de prevalência da doença hidática, os cistos parasitários são descritos como as lesões císticas mais comuns do baço ${ }^{1,5}$. Em áreas não endêmicas de hidatidose, os pseudocistos formam o grupo mais comum (75 a $80 \%$ dos casos), seguidos pelos cistos verdadeiros epidérmicos ${ }^{1-5}$. Um estudo anatomopatológico de Robbins, citado por Melo ${ }^{1}$, encontrou 32 casos de cistos epidérmicos em 42.327 autópsias.

A cirurgia videolaparoscópica tem surgido recentemente como uma alternativa à cirurgia aberta para tratamento de doenças esplênicas ${ }^{1-5}$. A retirada parcial da cápsula do cisto por via laparoscópica (descapsulação) vem sendo realizada com sucesso na última década. ${ }^{1-5}$ Apresentamos um caso de uma mulher jovem, portadora de cisto esplênico epidérmico, tratada por descapsulação por via laparoscópica.

\section{RELATO DO CASO}

Mulher, 25 anos, natural do Rio de Janeiro, tinha como queixa principal dor em hipocôndrio esquerdo de seis meses de duração, pequena intensidade, constante e sem outros sintomas associados. Os exames laboratoriais eram normais e a sorologia para doença hidática negativa. $\mathrm{O}$ exame ultra-sonográfico de abdome demonstrou uma formação cística de 42 x 39mm, em proximidade ao hilo esplênico e a tomografia computadorizada abdominal confirmou a presença de uma formação expansiva de paredes regulares e bem delimitadas medindo 40 x 36mm, com den- sidade de líquido, junto à cauda do pâncreas e ao hilo esplênico (Figura 1).

A paciente foi submetida ao procedimento laparoscópico em decúbito semilateral direito, utilizando-se um acesso $6 \mathrm{~cm}$ acima da cicatriz umbilical e três acessos subcostais (subxifóideo, linha médio-clavicular esquerda e axilar-anterior esquerda), encontrando-se um cisto de cápsula acizentada, localizado na superfície anterior e próximo ao hilo esplênico, pouco aderido às estruturas vizinhas. Foi realizada punção da cápsula do cisto, aspirando-se material espesso amarelado-translúcido, e,

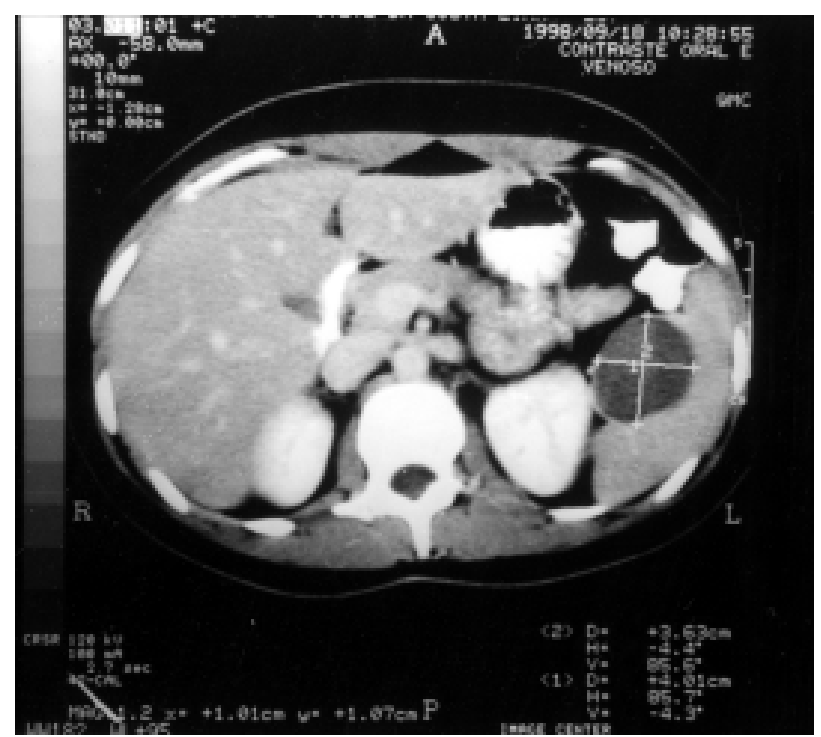

Figura 1 - Tomografia computadorizada abdominal mostrando a presença de imagem cística ovalada medindo 40x36mm em seu maior eixo, em contigüidade com o tecido esplênico, de limites bem definidos, próxima ao hilo esplênico e à cauda do pâncreas.

1. Professor Assistente do Departamento de Cirurgia Geral da Faculdade de Ciências Médicas da UERJ

2. Residente de Cirurgia Geral do Hospital Universitário Pedro Ernesto da UERJ

Recebido em 10/6/99

Aceito para publicação em 22/5/2000

Trabalho realizado no Departamento de Cirurgia Geral do Hospital Universitário Pedro Ernesto da Universidade do Estado do Rio de Janeiro - UERJ 
a seguir, foi efetuada a abertura e ressecção de toda a cápsula que não estava envolvida por tecido esplênico com tesoura e eletrocautério. O material aspirado foi submetido a exame bacteriológico e a pesquisa para fungos, sendo ambos os testes negativos. Houve boa evolução pós-operatória, com alta hospitalar após $24 \mathrm{~h}$. O exame histopatológico da cápsula do cisto revelou tecido fibroso denso com presença de epitélio simples cuboidal no revestimento interno. A paciente encontra-se assintomática após quatro meses de cirurgia.

\section{DISCUSSÃO}

As teorias sobre a formação dos cistos esplênicos epidérmicos suportam a origem neoplásica, a inclusão embriológica de peritônio na substância esplênica, a invaginação peritonial após rotura da cápsula esplênica e a dilatação de espaços linfáticos ${ }^{1,2}$. O quadro clínico usualmente descrito se compõe de dor abdominal vaga e persistente em quadrante superior esquerdo, porém tais cistos podem ser assintomáticos em até $30 \%$ dos $\operatorname{casos}^{1-3}$. Sintomas relacionados à compressão de órgãos adjacentes, como estômago, cólon esquerdo, rim esquerdo e artéria renal esquerda, também são descritos ${ }^{3}$. Apesar da raridade desta condição nos grandes centros urbanos do nosso país, a doença hidática deve estar incluída no diagnóstico diferencial dos cistos esplênicos. A orientação terapêutica dos cistos do baço deve estar baseada na história clínica e na origem do paciente, bem como no teste imunológico para hidatidose (radioimunoensaio), já que o tratamento mais aceito para os cistos parasitários é a esplenectomia total. A calcificação da parede do cisto, percebida à vista de uma radiografia simples, é uma característica comum dos cistos hidáticos e dos pseudocistos, quando comparados aos cistos epidérmicos ${ }^{1-3}$.

Várias são as opções terapêuticas para os cistos não parasitários e suas indicações permanecem controversas $^{1-5}$. A esplenectomia era apontada como o tratamento de escolha em todos os casos, mesmo quando assintomáticos, com a intenção de se evitar complicações, como rotura, hemorragia ou infecção. Admite-se, atualmente, que a descoberta de pequenos cistos assintomáticos (menores que $4 \mathrm{~cm}$ ) possa ser acompanhada conservadoramente $^{1,3}$. A punção e a aspiração percutânea com ou sem injeção de agentes esclerosantes não são consideradas satisfatórias devido aos riscos de hemorragia, infecção e recidiva. ${ }^{1}$ Com o maior entendimento da fisiologia do baço, as cirurgias conservadoras passaram a ser aplicadas no manejo terapêutico dos cistos e tanto as esplenectomias parciais como as descapsulações (laparotômicas e laparoscópicas) vêm sendo descritas como eficazes $^{1-5}$. As descapsulações foram aplicadas com sucesso tanto nos casos de cistos epidérmicos como nos de pseudocistos $^{1-5}$. Uma característica pré-operatória importante para a indicação da descapsulação laparoscópica é a localização superficial e anterior do cisto $^{3}$. Esta técnica deve ser levada em consideração para o tratamento das lesões císticas não parasitárias esplênicas por ser eficaz, pouco invasiva e por preservar o tecido esplênico, conforme demostrado neste caso.

\begin{abstract}
A rare case of primary splenic cyst is shown in a young woman who had a left subcostal abdominal pain. Abdominal echography and CT scan revealed a cyst of the anterior aspect of the spleen. A sorologic test for hidatic disease was negative. On the basis of a presumed diagnostic of nonparasitic cyst, the patient was referred to a laparoscopic decapsulation with excision of the cyst wall not covered by splenic tissue. The patient was discharged 24 hours later. Histological report revelead epidermoid cyst. The laparoscopic approach has being recently considered an effective and less invasive alternative in the treatment of splenic diseases. We demonstrated that it should be considered for the treatment of splenic cysts present in a superficial location, with the advantage of organ preservation.
\end{abstract}

Key Words: Splenic cyst; Spleen; Laparoscopic treatment.

\title{
REFERÊNCIAS
}

1. Melo VA, Alves Júnior A, Andrade LC et al. Cisto esplênico. Revisão da literatura e relato de dois casos. Rev Hosp Clin Fac Med S Paulo. 1995; 50:20. 289-293.

2. Alvarez GCA, Costa EM, Faria EN. Cisto esplênico nãoparasitário e não-neoplásico. Rev Col Bras Cirur 1998; 25:1. 64-65.

3. Calligaris L, Bortul M. Laparoscopic treatment of a nonparasitic splenic cyst: Case Report. Jour.Lap.Surg. 1996; 6:6. 431-433.

4. Trias M, Targarona EM, Espert JJ et al. Laparoscopic surgery for splenic disorders. Surg Endosc. 1998; 12:66-72.
5. Targarona EM, Martinez J, Ramos C et al. Conservative laparoscopic treatment of a posttraumatic splenic cyst. Surg Endosc 1995; 9:71-72.

Endereço para correspondência

Dr. Renato Maranhão de Albuquerque

Rua Lauro Muller, 128/903

22290-160 — Rio de Janeiro-RJ 